\title{
Impact of a Negative Breast Biopsy on Subsequent Breast Self-Examination Practice
}

\author{
Don P. Haefner ${ }^{a}$, Marshall H. Becker ${ }^{\mathrm{a}}$, Nancy K. Janz ${ }^{\mathrm{a}}$ and \\ Wilmer M. Rutt ${ }^{b}$
}

${ }^{a}$ Department of Health Behavior and Health Education, University of Michigan School of Public Health, Ann Arbor, Michigan and 'Department of Internal Medicine, Henry Ford Hospital, Detroit, Michigan (U.S.A.)

(Received February 17th, 1989)

(Accepted June 19th, 1989)

\begin{abstract}
Women who practice breast-self examination (BSE) occasionally detect breast lumps that are ultimately biopsied and found to be benign. This research examined the impact of a negative breast biopsy on subsequent BSE practice. A total of 655 women comprised three study groups: 88 women who discovered their breast problem by BSE; 179 women whose lump was identified by an individual/procedure in the health care system; and 393 women with no history of breast problems. Telephone interviews determined BSE practice for 6-month intervals prior to, and after, the benign biopsy experience. Among previously-regular practitioners, $21 \%$ of the self-discovered group and $16 \%$ of those whose lump was discovered in the health care system reduced their BSE practice below the recommended monthly interval following the benign biopsy. In contrast, among initiallynonregular practitioners, $29 \%$ of the self-discovered group, and $25 \%$ of the health care system group subsequently became regular BSE practitioners. Possible explanations are offered for these opposite shifts in BSE regularity, and some practical suggestions are provided for health care professionals who counsel women following a benign biopsy experience.
\end{abstract}

Keywords: breast self-examination; early detection; patient counseling.

\section{Introduction}

Although no one would deny the major benefits to the public's health and well-being derived from the adoption of professionally-recommended healthpromotive practices, there is increasing recognition that these behaviors carry the potential for untoward consequences [1,2]. For example, exercise has recently come under scrutiny because of its contributions to a variety of musculoskeletal ailments and pathophysiologic conditions [3]. Similarly, a sizable proportion of individuals who undergo occult-blood screening may ultimately

Correspondence to: Don P. Haefner, Department of Health Behavior and Health Education, University of Michigan School of Public Health, 1420 Washington Heights, Ann Arbor, Michigan 48109-2029, U.S.A. 
suffer iatrogenic morbidity (and even mortality), leading one investigator to conclude that the risks could outweigh the benefits for any age group [4].

Breast self-examination (BSE) is widely recommended as a useful screening technique for the early detection of breast cancer [5]. Women who practice BSE occasionally find lumps that are subsequently biopsied and found to be benign. Even though a negative biopsy represents a favorable medical outcome, women who have undergone such an experience may not perceive it in an entirely positive way. Discovery of a lump generally evokes considerable fear and anxiety, which continue until an uncomfortable surgical procedure is completed and the reassuring pathology report is communicated. Thus, upon reflection, the woman may perceive that having followed the recommended BSE practice has resulted in unnecessary emotional stress, discomfort, inconvenience, and cost for herself (and often her family).

Given this possible scenario, we hypothesized that women who regularly engage in BSE, find a lump, and have it biopsied with a benign outcome, would have a higher rate of discontinuance of regular BSE behavior than that found among regular BSE practitioners in the general population. In addition, we were interested in learning about subsequent BSE behavior when a benign lump was discovered by an individual or a procedure in the health care system (e.g. physician examination, mammogram).

Previous studies have focused on factors such as the extent to which BSE is performed [6,7], women's beliefs about BSE and breast cancer [8,9], how best to persuade women to practice BSE [10], and strategies for enhancing adherence to regular practice [11-14]. Little is known about the influence of discovery of a benign lump on subsequent practice of BSE. One investigation [15] of BSE practices and attitudes included a group of 33 women with previously-treated benign breast lumps; however, they did not obtain data on BSE practice prior to discovery of a lump, or on the means by which the lump was discovered. If negative biopsies were shown to have a deleterious influence on adherence to recommended BSE practice, such findings would have important implications for the development of patient education and counseling strategies to be used by health professionals.

\section{Method}

Two subject populations were identified from computerized rosters of patients at a large health care system that included a wide socioeconomic range: (1) women at least 21 years of age who had undergone a recent breast biopsy with a benign outcome (the biopsy group); and (2) women who had attended the general medicine clinic (the control group), matched with biopsygroup women on age (within 5 years), race, and clinic appointment date (within 15 days of biopsy date). The control group was established to determine the normal fluctuation in practice of BSE over time in the absence of a breast problem. Six months was used as the minimum elapsed period between breast biopsy/clinic visit and eligibility for the study. The biopsy group included women who had self-discovered their breast problem as well as women in whom the problem was discovered by the health care system. 
Each potential subject was contacted by telephone and invited to participate in a brief telephone survey on women's health practices. Verbal consent was obtained from all women agreeing to participate. The telephone interview included the following topics: (1) the respondent's perceived overall health status compared to other women her age; (2) any past history of breast problems (and for those with such a history, how the most recent breast problem was discovered, whether a biopsy was performed, and if so, with what outcome); and (3) the extent to which she engaged in breast self-examination. BSE practice was assessed for two time intervals: the 6-month period just preceding the breast biopsy or clinic appointment (Time 1), and the 6-month period immediately thereafter (Time 2). Of the 1250 women contacted over the 19month study period, $12 \%$ refused to participate, resulting in a study population of 1102 women ( 532 in the biopsy group, and 570 in the control group).

Every effort was made to implement survey research approaches designed to ensure valid self-reports. The nature of the study population and problem dictated our decision to use only female interviewers. Interviewers identified themselves as not being associated with the clinic, and assured subjects that interview responses would be kept strictly confidential. Interviewers were also trained to avoid making any value-laden comments concerning a subject's BSE practice or any other health-related behaviors.

Because our measure of BSE practice is dependent on the accuracy of participant recall, several procedures were employed to minimize the limitations of this approach. First, to avoid dependence on recollection of small differences, we have collapsed self-reported frequency of BSE into two categories: practice below, and practice at/above the usually-recommended frequency of once per month (the most conservative definition of regular practice). One would expect that a woman who engaged in regular BSE behavior could correctly recall that she examined herself at least once every month. Second, in order to avoid sensitizing respondents to our interest in the biopsy experience, interviewers referred to the month of the year when the study event (biopsy or clinic visit) took place, rather than to the event itself.

\section{Results}

To answer the major questions posed in this investigation, it was necessary to ensure that women in the biopsy group: (1) had experienced a breast problem that was subsequently biopsied and found to be benign approximately 6 months before the interview; and (2) had no previous history of breast problems. Examination of biopsy-group interview data resulted in exclusion from further analysis of 123 women who had undergone other breast biopsies and 5 who did not describe the biopsy outcome as benign. In addition, 87 women did not perceive that they ever had a breast problem, and 16 did not recall having had a biopsy.

The term "problem" may have posed a difficulty in that some women probably did not think that a benign biopsy outcome should be characterized as a "breast problem"; others may not have recognized the procedure as having been a "biopsy". It is also not uncommon to find individuals who, after a trau- 
matic health care experience, suppress recollection of the event. In any event, the study hypotheses and questions dictate inclusion only of respondents in this group who perceived that they had experienced a breast problem and a benign biopsy. I was also discovered that $177(30 \%)$ of women in the control group had experienced a previous breast problem, and they too were excluded from subsequent analysis.

Figure 1 describes how the breast problem was discovered among the 290 women comprising the biopsy group. Among the 111 women who said they had themselves found their breast problem, $28(25.2 \%)$ had done so by means other than BSE. Because the major research question involved the influence of discovery of a benign breast problem by BSE on subsequent regularity of practice, these 28 women were not included in further analyses. Among the 179 women whose breast problem was recognized by the health care system, almost $60 \%$ were identified by mammogram alone, and an additional $18 \%$ were ascertained by a combination of health-provider breast examination and mammogram. The remaining analyses are therefore based on a total of 655 study participants: a biopsy group, consisting of 83 women who self-discovered a breast problem by BSE and 179 women in whom the breast problem was identified by the health care system, and a control group of 393 women with no history of breast problems.

The sociodemographic and health-related characteristics of the final study participants are shown in Table I. Results for the biopsy group are presented in total, as well as divided into self-discovered and health-care-discovered subgroups. The mean age of the entire sample was 49 , and over $50 \%$ of the participants had more than a high school education. Approximately $80 \%$ were white, and the majority of women perceived their health status as "above average" or "average" compared to other women their age.

There were no statistically significant differences between the biopsy and control groups, with one exception. With respect to the practice of BSE during

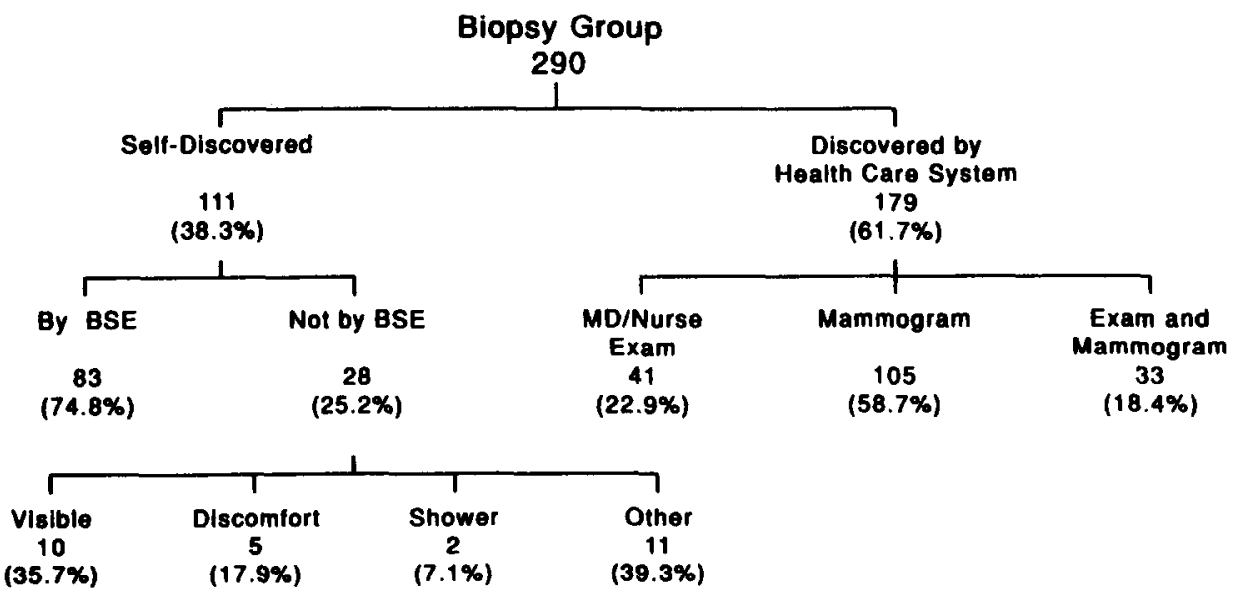

Fig. 1. Biopsy group: how breast problem was discovered. 
TABLE I

SOCIODEMOGRAPHIC AND HEALTH-RELATED CHARACTERISTICS PARTICIPANTS BY STUDY GROUP

\begin{tabular}{|c|c|c|c|c|}
\hline \multirow[t]{2}{*}{ Characteristic } & \multicolumn{3}{|l|}{ Biopsy group } & \multirow{2}{*}{$\begin{array}{l}\text { Control group } \\
\% \\
\text { Total group } \\
(N=393)\end{array}$} \\
\hline & $\begin{array}{l}\% \\
\text { Total group } \\
(N=262)\end{array}$ & $\begin{array}{l}\% \\
\text { Self-discovered } \\
(N=83)\end{array}$ & $\begin{array}{l}\% \\
\text { Discovered } \\
\text { health care sys } \\
(N=179)\end{array}$ & \\
\hline \multicolumn{5}{|l|}{ Age (years) } \\
\hline$<40$ & 24.8 & 45.8 & 15.1 & 29.8 \\
\hline $40-60$ & 48.9 & 47.0 & 49.7 & 44.0 \\
\hline$>60$ & 26.3 & 7.2 & 35.2 & 26.2 \\
\hline \multicolumn{5}{|l|}{ Education } \\
\hline$<$ High school & 12.2 & 9.6 & 13.4 & 14.2 \\
\hline High school & 32.4 & 33.7 & 31.8 & 31.3 \\
\hline$>$ High school & 55.3 & 56.6 & 54.7 & 54.4 \\
\hline$\%$ White & 80.8 & 79.3 & 81.5 & 80.1 \\
\hline \multicolumn{5}{|l|}{ Health status } \\
\hline Above average & 49.4 & 53.1 & 47.8 & 49.3 \\
\hline Average & 41.8 & 41.0 & 42.1 & 39.3 \\
\hline Below average & 8.8 & 6.0 & 10.1 & 11.3 \\
\hline \multicolumn{5}{|l|}{ BSE practice Time 1} \\
\hline \% Practice some BSE & 67.6 & 96.0 & 57.4 & 69.6 \\
\hline$\%$ Practice ideal BSE & 39.0 & 61.5 & 28.4 & 29.2 \\
\hline
\end{tabular}

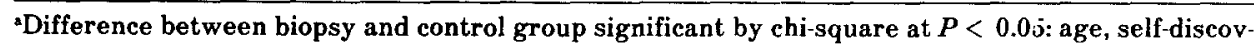
ered vs. control; practice some BSE; self-discovered vs. control; practice ideal BSE; total biopsy group vs. control, self-discovered vs. control.

the 6 months prior to the biopsy or visit to the medical clinic, the study groups did not differ when practice was assessed as "some versus none", but did differ significantly in favor of the biopsy group when practice was assessed as "ideal (i.e. six or more time in a 6-month period) versus all others". Moreover, if one examines these characteristics among the three study groups (i.e. self-discovered by BSE, discovered by the health-care system, and control group) some further differences emerge. The self-discovered group are significantly younger than the control group, and not surprisingly, also significantly more likely to have engaged in the regular practice of BSE prior to identification of the breast problem.

It is also interesting to note that the health-care-discovered group had the largest percentage of women who did not practice BSE at all $(42.6 \%)$ during the 6 -month period just preceding the benign breast biopsy. The $114(29.1 \%)$ of the 392 women in the control group reporting regular BSE practice at Time 1 is 
consistent with previous findings on the percentage of women in the general population practicing BSE at the recommended frequency [16].

In order to test our central hypothesis, we examined BSE practice at Time 2 among initially-regular BSE practitioners in the self-discovered group versus the control group. The results presented in part A of Table II support our concern that women who regularly practiced BSE and self-discovered their breast problem were more likely to become nonregular BSE practitioners following the benign biopsy experience (i.e. the percent that changed to less than ideal practice was $21.6 \%$ in the self-discovered group, compared to $9.7 \%$ in the control group, $P<0.05$ ).

However, to complete the picture, the next step in our analysis was to determine if women who had self-discovered their breast problem but who had not been regular BSE practitioners would continue that pattern or would become regular practitioners. Findings shown in part B of Table II reveal an

\section{TABLE II}

CHANGE IN REGULARITY OF BSE PRACTICE OVER TIME, BY STUDY GROUP

\begin{tabular}{llll}
\hline Study group & Time 2 & & \\
\cline { 2 - 4 } & Nonregular & Regular & Changed practice \\
& BSE practice & BSE practice & over time $(\%)$ \\
& $(0-5)$ & $(\geqslant 6)$ &
\end{tabular}

\begin{tabular}{|c|c|c|c|}
\hline \multicolumn{4}{|c|}{ (A) Among regular BSE practitioners $>6$ at Time 1} \\
\hline $\begin{array}{l}\text { Self-discovered } \\
(N=51)\end{array}$ & 11 & 40 & $-21.6^{\mathrm{a}}$ \\
\hline $\begin{array}{l}\text { Control } \\
(N=114)\end{array}$ & 11 & 103 & -9.7 \\
\hline \multicolumn{4}{|c|}{ (B) Among nonregular BSE practitioners $(0-5)$ at Time 1} \\
\hline $\begin{array}{l}\text { Self-discovered } \\
(N=31)\end{array}$ & 22 & 9 & $+29.0^{\mathrm{a}}$ \\
\hline $\begin{array}{l}\text { Control } \\
(N=278)\end{array}$ & 250 & 28 & +10.1 \\
\hline \multicolumn{4}{|c|}{ (C) Among regular BSE practitioners $>6$ ) at Time 1} \\
\hline $\begin{array}{l}\text { Discovered by health care system } \\
(N=50)\end{array}$ & 8 & 42 & -16.0 \\
\hline $\begin{array}{l}\text { Control } \\
(N=114)\end{array}$ & 11 & 103 & -9.7 \\
\hline \multicolumn{4}{|c|}{ (D) Among nonregular BSE practitioners $(0-5)$ at Time 1} \\
\hline $\begin{array}{l}\text { Discovercd by health care system } \\
(N=126)\end{array}$ & 95 & 31 & $+24.6^{\mathrm{a}}$ \\
\hline $\begin{array}{l}\text { Control } \\
(N=278)\end{array}$ & 250 & 28 & +10.1 \\
\hline
\end{tabular}

Difference between biopsy and control group significant by chi-square at $P<0.05$. 
TABLE III

SUMMARY OF CHANGES IN BSE PRACTICE FROM TIME 1 TO TIME 2, BY STUDY GROUP

\begin{tabular}{|c|c|c|c|}
\hline \multirow{2}{*}{$\begin{array}{l}\text { BSE practice } \\
\text { Time } 1 \rightarrow \text { Time } 2\end{array}$} & \multicolumn{3}{|l|}{ Study group } \\
\hline & Self-discovered $(\%)$ & $\begin{array}{l}\text { Discovered by } \\
\text { health care } \\
\text { system }(\%)\end{array}$ & Control (\%) \\
\hline Nonregular $\rightarrow$ regular & 29.0 & 24.6 & 10.1 \\
\hline Regular $\rightarrow$ nonregular & 21.6 & 16.0 & 9.7 \\
\hline
\end{tabular}

opposite shift in BSE behavior for this group of women, i.e. they were significantly more likely to become regular BSE practitioners at Time 2 than were women in the control group $(29.0 \%$ vs. $10.1 \%, P<0.05)$.

Next, we wondered if these shifts in BSE behavior related to regularity of prior practice would also occur in the group of women whose problem was identified within the health care system. Examination of part $\mathrm{C}$ of the Table II reveals that, of the 50 women who were regular BSE practitioners at Time 1,8 $(16.0 \%)$ became nonregular during the subsequent 6 -month period. This percent decline in BSE behavior is not significantly different than that reported among women in the control group (9.7\%). However, the impact of discovery of a breast problem within the health care system among women had not been performing BSE on a regular basis (part D) was strikingly different. In this group, $24.6 \%$ (31 of 126 ) become regular practitioners following the benign biopsy. This observed increase in regular BSE is significantly higher than the $10.1 \%$ obtained for the control group $(P<0.05)$.

Table III summarizes the percent change in BSE practice from Time 1 to Time 2 by study group. Regardless of whether one focuses on the change from nonregular to regular practice, or from regular to nonregular practice, women in the self-discovered group experienced the highest percent shifts in BSE behavior relative to the other two study groups. Finally, our results show about a 10\% shift in BSE practice in both directions occurring in women who do not experience any breast abnormality (i.e. almost equal numbers of women become regular practitioners as reduce their practice levels below the recommended frequency).

\section{Discussion}

These findings suggest that the impact of a benign biopsy on frequency of BSE practice is influenced by the regularity of prior practice. When the lump was self-discovered, among regular practitioners the benign biopsy experience was followed by a reduction in BSE to below ideal frequency; among nonregular practitioners, the event led to an increase in practice to the recommended monthly interval. Our data also indicate a considerable impact on BSE when the 
benign lump was discovered within the health care system. The same pattern emerges as was obtained for the self-discovered lumps - a depressing influence on subsequent behavior by initially-regular practitioners but a dramatic facilitating effect on subsequent practice by initially nonregular practitioners. Such shifts do not simply reflect regression toward the mean, since they are significantly greater than those displayed by the control group.

How can one account for these divergent findings? In the case of regular practitioners, we had hypothesized a decline in BSE because the experience would be perceived as a negative one. It may be that, for nonregular practitioners, the finding of a lump may have suggested to the women the notion that, had she practiced BSE more frequently, she could have identified the problem earlier.

Indirect support for this explanation can be derived from further analyses of data obtained from those women who were not engaging in BSE at all at Time 1 , but who were practicing with some frequency at Time 2 . These women were asked to indicate the particular reason or incident that got them started doing BSE. The majority of these women in the biopsy group $(68.6 \%)$ reported that it was "awareness of the breast problem" that stimulated the behavior change lother reasons included "having a mammogram" $(23.3 \%)$ and "physician recommendation" $(7.0 \%))$. By contrast, the most common reason offered by women in the control group who had begun BSE within the past year was "physician recommendation" ( $35.3 \%)$, followed by "family or friend with a breast problem" $(17.6 \%)$ and "general health recommendation" $(17.6 \%)$.

It is also possible that these 2 groups of women received different interventions from the health care system following the benign biopsy experience. In the case of nonregular BSE practitioners who self-discovered a lump, the health care team may have reinforced the women's efforts but suggested that the frequency of BSE be increased to the recommended monthly regime. On the other hand, with regular BSE practitioners, the health care professional may not have felt any need to discuss BSE behavior, assuming the woman would continue her previous regular practice; thus, in the absence of reinforcement, and in the face of the anxiety and physical discomfort associated with the biopsy, this group may have decreased their regularity. In any event, the decrease in frequency of BSE practice by the initially-regular group poses a challenge for health professionals concerning how to counter this undesirable trend.

There were only a small number of women in either the biopsy group or the control group who were practicing BSE during the first 6-month interval and who stopped completely during the subsequent 6 -month period. In both groups, the most common reasons given for stopping included "felt uncomfortable doing it," "regular physician check-up sufficient," and "lack of confidence in doing BSE." These results parallel those of Amsel et al. [16] who found selfconfidence and knowledge variables to be related to frequency of BSE practice.

Research involving the assessment of BSE frequency has always depended upon participant cooperation, evoking the usual problems surrounding selfreport and memory - and this study required subjects to recall practice for 
two time intervals. However, by employing trained female interviewers, assuring confidentiality, using collapsed frequency categories, and removing reference to the biopsy experience, we believe we have minimized this limitation. Furthermore, the fact that we found change in frequency of BSE practice over time reported by women in the control group suggests that participants' responses did reflect careful consideration of their behavior rather than simple repetition of their initial response.

Our data demonstrated the significant impact of a benign biopsy on subsequent BSE practice. Health care professionals who come into contact with women having had such an experience should not assume that regular practitioners will continue BSE at the recommended frequency. The time at which the provider transmits the good news about the negative biopsy can be utilized as a "pedagogic moment," presenting an opportunity to:

(1) compliment the self-discoverers for having identified the problem and seeking professional diagnosis and helping them to interpret the experience in a positive way;

(2) reinforce those who were previously regular practitioners, and point out to nonregular practitioners the importance of increasing BSE frequency to recommended levels;

(3) include as a routine part of counseling some assessment of relevant knowledge and self-efficacy dimensions (with subsequent intervention where necessary); and

(4) in cases where the lump was discovered by the health care system, to discourage sole reliance on physician examination and/or mammogram, emphasizing instead BSE as the first line of defense.

\section{Acknowledgement}

This research was supported in part by the fund for Henry Ford Hospital.

\section{References}

1 Levin LS Every silver lining has a cloud: The limits of health promotion. Social Policy 1987; 18: $57-60$.

2 Becker MH. The tyranny of health promotion. Public Health Rev 1986; 14: 15 - 25.

3 Koplan JP, Siscovick DS, Goldbaum GM. The risks of exercise: A public health view of injuries and hazards. Public Health Rep 1985; 100: 189- 195.

4 Frank JW. Occult-blood screening for colorectal carcinoma: The risks. A J Prev Med 1985; 1: $25-32$.

5 American Cancer Society. Cancer Facts and Figures -- 1987. New York: American Cancer Society, 1987.

6 Huguley CM, Brown RL. The value of breast self-examination. Cancer 1981; 47:989-995.

7 Winberg AD, Spiker CA, Ingersoll RW, Hoersting RA. Public knowledge and attitudes toward cancer: Their role in health decisions and behaviors. Health Values 1982; 31: $37-142$.

8 Hallal JC. The relationship of health beliefs, health locus of control, and self concept to the practice of breast self-examination in adult women. Nurs Res 1982; 31 : $137-142$.

9 Stillman MJ. Women's health beliefs about breast cancer and breast self-examination. Nurs Res 1877; 26: $121-127$. 
10 Worden JK, Costanza MC, Foster RS, et al. Content and context in health education: Persuading women to perform breast self-examination. Prev Med 1983; 12: 331-339.

11 Assaf AR, Cummings KM, Graham S, et al. Comparison of three methods of teaching women how to perform breast self-examination. Health Educ Q 1985; 12: 259-272.

12 Craun AM, Deffenbacher JL. The effects of information, behavioral rehearsal, and prompting on breast self-exams. J Behav Med 1987; 10: $351-365$.

13 Grady KE, Goodenow C, Borkin JR. The effect of reward on compliance with breast self-examination. J Behav Med 1986; 11: 43-57.

14 Smith PC, Hailey BJ. Compliance with instructions for regular breast self-examination. J Compl Health Care 1988; 3: 151-161.

15 Strauss LM, Solomon LJ, Costanza MC, et al. Breast self-examination practices and attitudes of women with and without a history of breast cancer. J Behav Med 1987; 10: 337 - 350 .

16 Amsel Z, Grover PK, Balshem AM. Frequency of breast self-examination practice as a function of physician reinforcement. Patient Educ Counsel 1985; 7: 147-155. 